\title{
Association of Various Risk Factors in Candida Infection in a Tertiary Care Hospital
}

\author{
M.V. Natasha* and U. Nawaz \\ Department of Microbiology, Gulbarga Institute of Medical Sciences, Gulbarga, India \\ *Corresponding author
}

\section{A B S T R A C T}

Keywords

Candida,

Immunosuppressive agents, Diabetes mellitus, HIV

Article Info

Accepted:

17 October 2019

Available Online:

10 November 2019
Candida is a part of the normal flora in healthy individuals, and is usually confined to the skin and mucosal surfaces of the oral cavity, gastrointestinal and urogenital tracts, and vagina. However it can cause a wide variety of infections in immunosuppressed patients of long term broad - spectrum antibiotics, steroids or other immunosuppressive agents, diabetes mellitus, AIDS, Malignancy, Neutropenia. Although the majority of infections are caused by Candida albicans, Non-C. albicans Candida (NCAC) species are emerging as important pathogen in humans. The present study included 130 clinical isolates which showed gram positive budding yeasts cells with or without pseudohyphae. We correlated Candida isolation with various risk factors and found that $54 \%$ of the patients from whom candida was isolated had been treated with $>2$ antibiotics, $15 \%$ treated with $>3$ antibiotics, $17 \%$ Diabetis Mellitus, $16 \%$ Neutropenia, $8 \%$ Tuberculosis and Treatment with Steroids, $6 \%$ Malignancy, $2 \%$ HIV.

\section{Introduction}

Several Candida species most notably C.albicans are ubiquitous human commensals. They become pathogenic in situations where the hosts resistance to infection is lowered locally or systematically. Two major medical events revived in candida infections were introduction of antibacterial drugs during the second half of twentieth century, broad spectrum antibiotics acts as predisposing factors for mycotic infections by causing imbalance of hosts microflora in favour of fungi upon which they have no inhibitory activity $^{2}$.The second event was increase in the prevalence of immunosupressed patients as a result of chemotherapy or AIDS which led to increase in incidence of Candida infections.

\section{Host defenses}

The oral cavity possesses physical barriers such as epithelial cells, saliva and salivary immunoglobulin (IgA), lysozyme, histidinerich polypeptide, lactoferrin and lactoperoxidase for antagonistic action against Candida overgrowth. Epidermal keratinocytes play an important role in the cutaneous immune response through the production of cytokines and chemokines, including interferon (IFN) Inducible protein 10 (IP-10), prostaglandin E2 may be a major predisposing factor for diminishing IFNc-induced IP-10. 
In mucosal (chronic mucocutaneous and gastrointestinal) candidiasis, T-cell (CD4+and CD8+) and cell-mediated immunity is the predominant host defence mechanism. Vaginal candidiasis is affected by T-cell response.

Poor cellular transportation of antifungal agents and inadequate immune response are the major factors that allow yeasts to colonize in immunocompromised patients such as AIDS.

The role of neutrophil activity as a main defense against systemic Candida infection has been supported by the significant incidence of disseminated infection during chemotherapy-induced granulocytopenia in patients with hematologic malignancies. $T$ cell in the prevention of mucocutaneous candidiasis has been shown by the development of chronic infections in children with altered cell-mediated immunity and in patients with acquired immunodeficiency syndrome. Alterations in cutaneous or mucosal barriers, provide a portal of entry, also increased the incidence of infections like candida endocarditis and endophthalmitis in intravenous drug abusers and in patients with indwelling catheters or extensive destruction of the skin by deep bums. An increased incidence of disseminated candidiasis is associated with altered gastrointestinal (GI) mucosa resulting from drug-induced or tumorinduced GI damage in patients with hematologic malignancies ${ }^{3}$

\section{Materials and Methods}

A total of 130 Candida species isolated from clinical samples like urine, pus, sputum, blood, oral swabs, vaginal swabs, endotracheal aspirates, endotracheal tips, were included in this study. The Study was conducted from Jan 2017 to Dec 2017. Data of patients regarding the use of long term broad - spectrum antibiotics, steroids or other immunosuppressive agents, diabetes mellitus, AIDS, Malignancy, Neutropenia, radiotherapy, organ transplant, new diagnostic and therapeutic procedures to patients, such as urinary indwelling catheters, nephrostomy tubes, hemodialysis, previous surgery were collected at enrolment.

Direct Examination of the clinical specimen using $10 \%$ and $20 \% \mathrm{KOH}$ was done by Wet mount preparation. The fungal elements ie budding yeasts cells pseudohyphae and hyphae were appreciated. Gram staining was done for all isolates which showed creamy pasty white growth to look for gram positive budding yeasts cells.

Samples showing Gram positive yeast like budding cells were inoculated using standard loops on Sabouraud's Dextrose Agar (SDA) containing chloramphenicol, incubated at $37^{\circ} \mathrm{C}$ and examined at the end of 24 and 48 hours of incubation. SDA slants were incubated at $37^{\circ} \mathrm{C}$ and examined twice a week to look for the growth of cream coloured pasty colonies suggestive of Candida species.

\section{Inclusion criteria}

Clinical samples like urine, pus, sputum, blood, oral swabs, vaginal swabs, endotracheal aspirates, endotracheal tips, which showed gram positive budding yeasts cells were included in this study.

Exclusion criteria: Contamination, Normal commensals

\section{Results and discussion}

Out of 130 Candida species isolated $54 \%$ of the patients from whom candida was isolated had been treated with $>2$ antibiotics, $15 \%$ had been treated with $>3$ antibiotics, $17 \%$ had Diabetis Mellitus, $16 \%$ had Neutropenia, $8 \%$ had Tuberculosis and $8 \%$ in those treated with 
steroids, 6\% had malignancy, 2\% had HIV. Isolation of $C$. albicans was $16 \%$ among HIV patients. C. tropicalis (32\%) and C. glabrata (32\%) most commonly isolated Candida spp in HIV infected individuals

In a study conducted by Kao et al., risk factors associated were antibacterial therapy (68\%), steroid therapy $(40 \%)$, neutropenia $(13 \%)^{10}$ while a study conducted by Verma (2003) showed association with broad-spectrum antibiotics (42.8\%) immunosuppressive therapy $(23.8 \%)$, neutropenia $(14.3 \%)^{11}$ which was similar to our present study.

Table.1 Risk factors associated with Candida infections

\begin{tabular}{|l|c|c|}
\hline Risk factor & Number & Percentage \% \\
\hline Diabetes Mellitus & 23 & 17 \\
\hline Tuberculosis & 11 & $\mathbf{8}$ \\
\hline HIV & 3 & 2 \\
\hline Malignancy & 9 & 6 \\
\hline Neutropenia & 22 & $\mathbf{1 6}$ \\
\hline Treatment with steroids & 11 & $\mathbf{8}$ \\
\hline Treatment with $>\mathbf{2}$ antibiotics & $\mathbf{7 0}$ & $\mathbf{5 4}$ \\
\hline
\end{tabular}

Fig.1 Risk factors associated with Candida infections

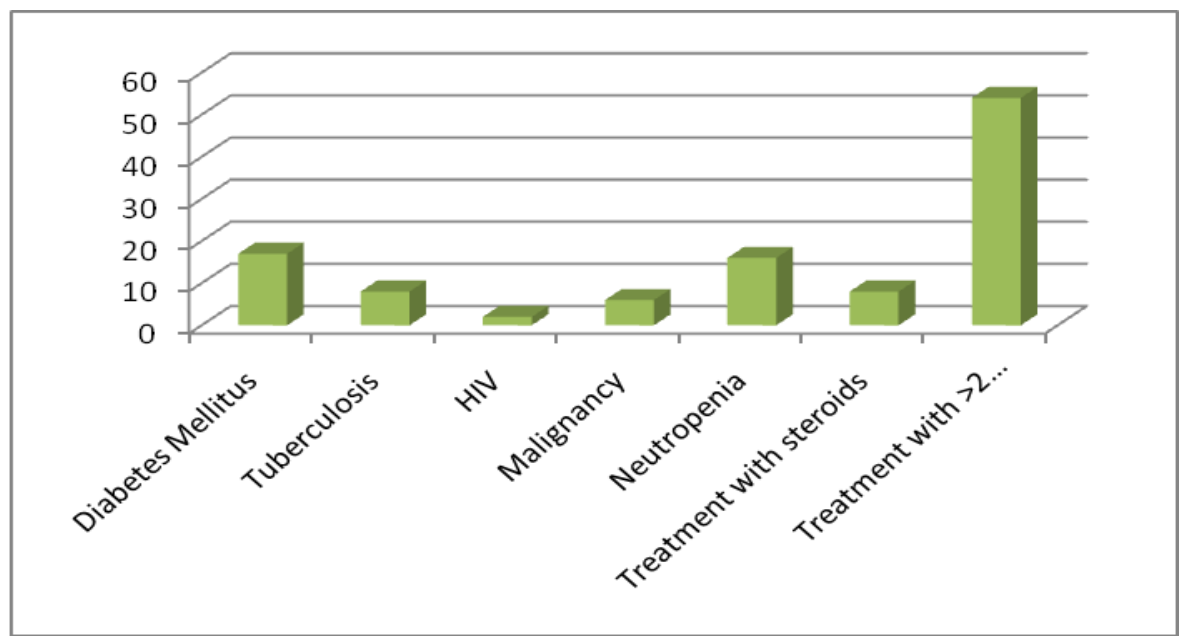

In conclusion, Candida spp. is one of the most frequent pathogens isolated in bloodstream infections, associated with significant morbidity and mortality in hospitalized patients. Candida species is more common in patients on multiple broad spectrum antibiotics, patients with Diabetes mellitus.

\section{References}

1. Chander J. Candidiasis in Text book of medical mycology. $3^{\text {rd }}$ edition. : Mehta pub 2008: 267-290.

2. Chakrabarti A, Shivprakash M. Laboratory Diagnosis. In Medical Mycology Laboratory Procedures. 2005: 17-70.

3. M. A. Pfaller and D. J. Diekema Epidemiology of Invasive Candidiasis: a Persistent Public Health Problem Clin. Microbiol. Rev. 2007, 20(1):133 
4. Richards M J, Edwards JR, Culver DH, Gaynes RP. Nosocomial infections in medical intensive care units in the United States. National Nosocomial Infections Surveillance System. Crit Care Med 1999;27: 887-892.

5. Ruan SY, Chen SY, Hsuek PR. Persistent Candida parapsilosis funguria associated with an indwelling urinary tract stent for more than 7 years. J Med Microbiol 2008; 5: 1585-7.

6. Sobel JD, Kauffman CA, McKinsey D, Zervos M, Vazquez JA, Karchmer AW et al. Candiduria: A randomized, doubleblind study of treatment with fluconazole and placebo. Clin Infect Dis 2000; 30: $19-24$.

7. Larone D H. Medically Important Fungi; A guide to identification, Washington, DC. ASM Press.2002; 328-329
8. W G Merz Candida albicans strain delineation. Clin. Microbiol. Rev. 1990, 3(4): 321.

9. RJ Kothavade, MM Kura, AG Valand, MH. Panthaki. Candida tropicalis: its prevalence, pathogenicity and increasing resistance to fluconazole. J Medl Microbiol (2010), 59, 873-880

10. Kao AS, Brandt ME, Pruitt WR, Conn LA, Perkins BA, Stephens DS, et al. The epidemiology of Candidaemia in two United States cities: results of a population-based active surveillance. Clin Infect Dis 1999; 29: 1164-70.

11. Verma AK, Prasad KN, Manisha S, Dixit AK, Ayyagari A. Candidaemia in patients of a tertiary health care hospital from north India. Ind J Med Res 2003; 117: 122-128.

\section{How to cite this article:}

Natasha, M.V. and Nawaz, U. 2019. Association of Various Risk Factors in Candida Infection in a Tertiary Care Hospital. Int.J.Curr.Microbiol.App.Sci. 8(11): 2171-2174. doi: https://doi.org/10.20546/ijcmas.2019.811.251 